\title{
Non-syndromic hereditary gingival fibromatosis
}

\author{
Ravi Prakash Sasankoti Mohan, Sankalp Verma, Neha Agarwal, Udita Singh
}

Department of Oral Medicine \& Radiology, Kothiwal Dental College \& Research Center, Moradabad, Uttar Pradesh, India

\section{Correspondence to} Dr Ravi Prakash Sasankoti Mohan, sasan_ravi@rediffmail. com

\section{SUMMARY}

Hereditary gingival fibromatosis is a rare condition characterised by severe gingival hyperplasia that can occur as an isolated disease or as part of a syndrome or chromosomal abnormality. In severe cases, the gingival enlargement may cover the crowns of teeth and cause severe aesthetic, emotional and functional impairment. This case report gives an overview of gingival fibromatosis in a 22-year-old male patient who presented with generalised gingival enlargement.

\section{BACKGROUND}

Hereditary gingival fibromatosis (HGF) is the rare, benign, non-inflammatory fibrotic enlargement of the maxillary or mandibular arches associated by familial aggregation also known as gingivomatosis elephantiasis, idiopathic gingival fibromatosis and hereditary gingival hyperplasia. ${ }^{1-3}$ It was recognised probably more than a century ago, the first case was reported by Goddard and Gross in $1856 .{ }^{2}$ Men and women are equally affected at a phenotypic frequency of 1:750 000 with varying intensity and expressivity even in individuals within the same family. ${ }^{3-7}$ HGF manifests as an autosomal dominant or less commonly, an autosomal recessive mode of inheritance. ${ }^{8-10}$

The hyperplastic gingiva usually presents a normal colour and has a firm consistency with abundant stippling. ${ }^{3} 5$ The gingival enlargement usually coincides with the eruption of the permanent dentition although it may occur during the eruption of primary dentition or rarely at birth. ${ }^{3}$ It may be localised (nodular) or generalised (symmetric), thus potentially interfering with speech, closure of the lips and mastication resulting in both aesthetic and functional problems. $^{25}$ The gingival enlargement may occur alone or in conjunction with other abnormalities, as part of a syndrome, most commonly in association with hypertrichosis, mental retardation, hearing loss and abnormalities of extremities, particularly of the fingers and toes. ${ }^{4} 67$ It may be easy for a dentist to arrive to a clinical diagnosis of gingival enlargement if the cause is clearly evident but at times it becomes necessary to seek medical advice to explore the cause and identify the underlying diseases, drug interactions or the natural body changes to develop an effective treatment plan. When the exact cause cannot be elucidated, it become challenging to the dentist to establish an accurate diagnosis. In this article we presented a case report on non-syndromic HGF.

\section{CASE PRESENTATION}

A 22-year-old man along with his younger sister reported to the outpatient department of our dental school reporting of pain and swelling in the gums and an inability to chew food (figure 1A,B). The patient was also concerned about the progressively increased spacing between his upper front teeth and their movement away from their original positions (figure 1C). Further history revealed that he had first noticed the swelling after the eruption of his permanent teeth. The swelling slowly progressed involving the gingiva in both the arches. There was difficulty in phonation and mastication with poor aesthetics.

On general physical examination there was presence of syndactyly of middle and ring fingers of both right and left hand (figure 1D).

The medical and drug history of both patients was non-contributory. The patient revealed a positive family history as his younger sister had similar gingival enlargement.

Radiographical examination in the form of panoramic view revealed no periodontal involvement (figure 2A). Histopathological features revealed highly fibrous connective tissue, with haphazardly arranged dense collagen bundles, numerous spindleshaped fibroblasts and connective tissue that is relatively avascular. Thickened, acanthotic and hyperkeratotic stratified squamous epithelium was also present with elongated rete ridges (figure 2B).

The intraoral examination of patient's sister revealed generalised, severe gingival overgrowth involving both the mandibular and maxillary arches. The gingival overgrowth was seen as firm, dense, fibrous and painless enlargement with normal gingival colour (figure 3A-D).

\section{INVESTIGATIONS}

A radiographical examination in the form of panoramic view revealed no periodontal involvement (figure 2A). Histopathological features revealed highly fibrous connective tissue, with haphazardly arranged dense collagen bundles, numerous spindleshaped fibroblasts, and connective tissue that is relatively avascular. Thickened, acanthotic and hyperkeratotic stratified squamous epithelium was also present with elongated rete ridges (figure $2 \mathrm{~B}$ ).

\section{DIFFERENTIAL DIAGNOSIS}

- Drug induced gingival enlargement.

- Scurvy.

- Sarcoidosis.

- Crohn's diseases.

- Cowden's syndrome.

- Amyloidosis.

\section{TREATMENT}

In our case, the patient was referred to the department of periodontology for maintenance of oral hygiene as well as surgical excision of the gum tissue. 

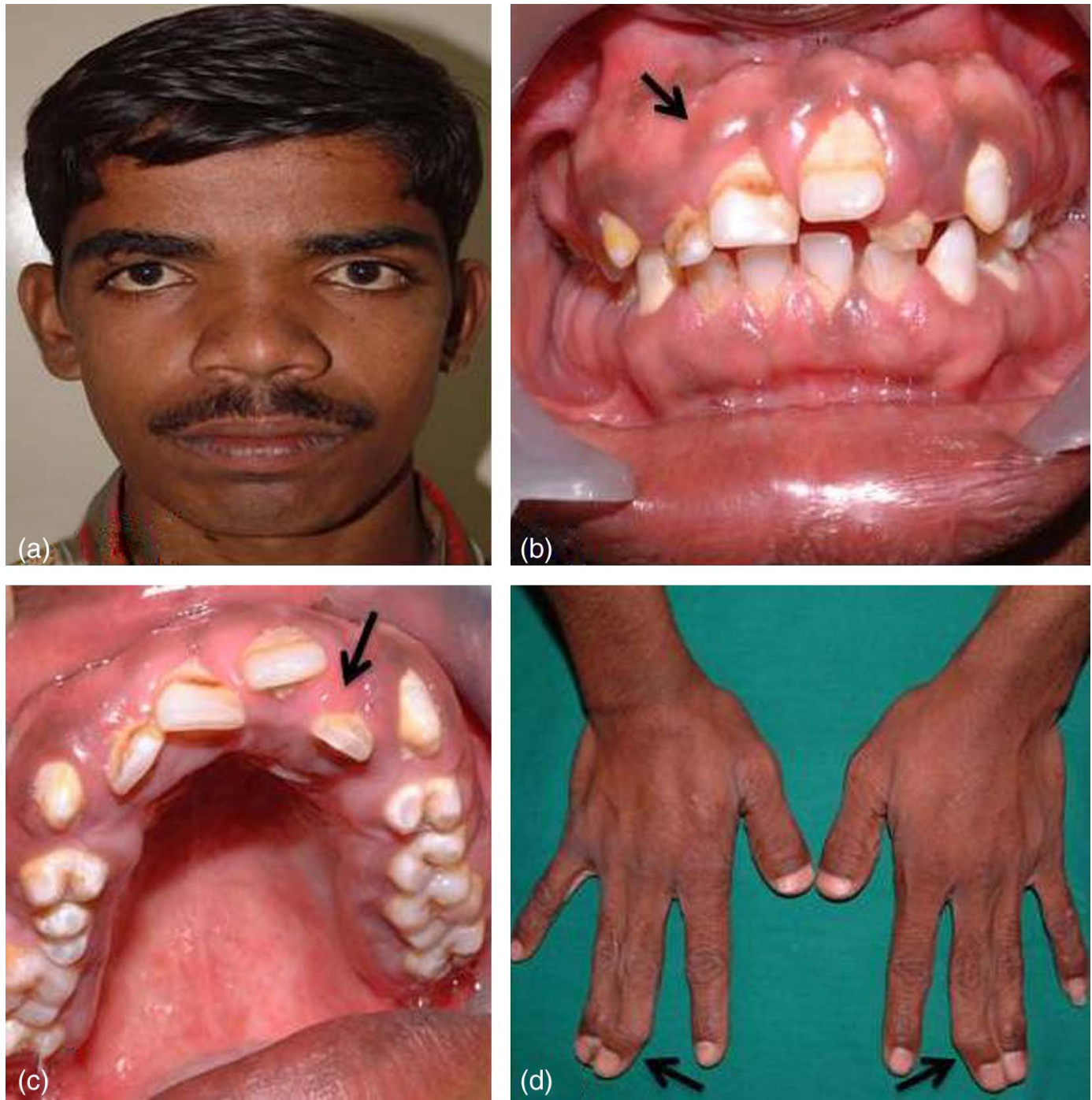

Figure 1 (A) Facial profile photograph of a 22-year-old male patient. (B) Intraoral photograph showing swollen gums. (C) Progressively increased spacing between his upper front teeth and their movement away from their original positions. (D) The presence of syndactyly of middle and ring fingers of the right as well as the left hand.

\section{OUTCOME AND FOLLOW-UP}

The prognosis for the current case was fair.

\section{DISCUSSION}

HGF is a rare, benign, non-haemorrhagic fibrous enlargement of gingival tissue. It was previously called elephantiasis gingiva, hereditary gingival hyperplasia and hypertrophic gingiva. ${ }^{2} 11$
Men and women are equally affected at a phenotype frequency of 1:750000 with varying intensity and expressivity even in individuals within the same family. ${ }^{3}$

HGF manifests as an autosomal dominant or less commonly, an autosomal recessive mode of inheritance. ${ }^{8-10}$ Autosomal dominant non-syndromic forms have been genetically linked to the chromosome 2p21-p22 and 5q13-q22. ${ }^{8}$ Recently, a
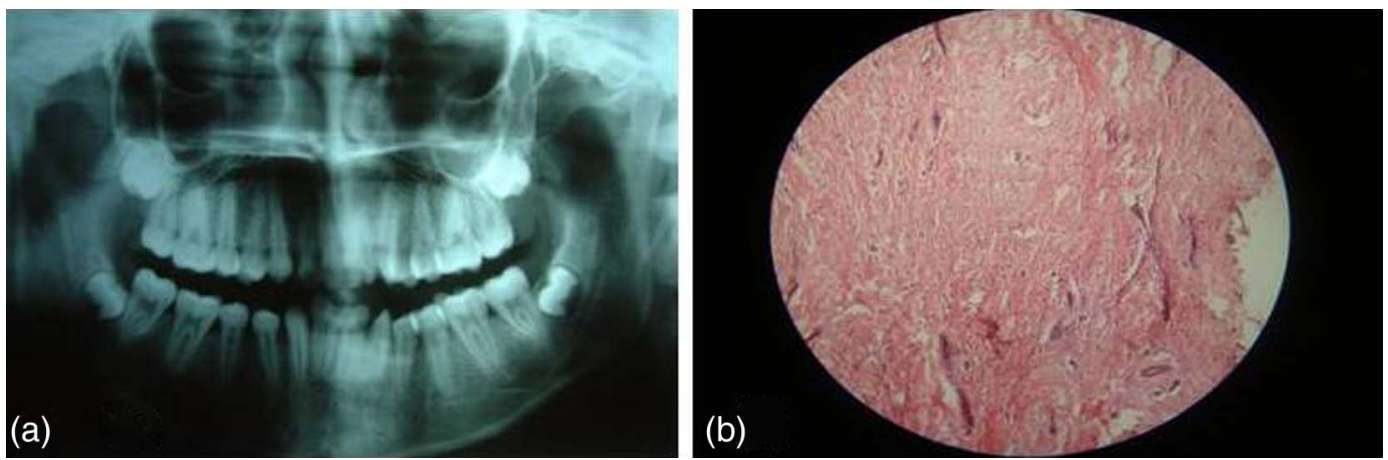

Figure 2 (A) Orthopantomogram of a 22-year-old male patient revealed no periodontal involvement. (B) Histopathological features revealed highly fibrous connective tissue, with haphazardly arranged dense collagen bundles, numerous spindle-shaped fibroblasts, with elongated rete ridges. 

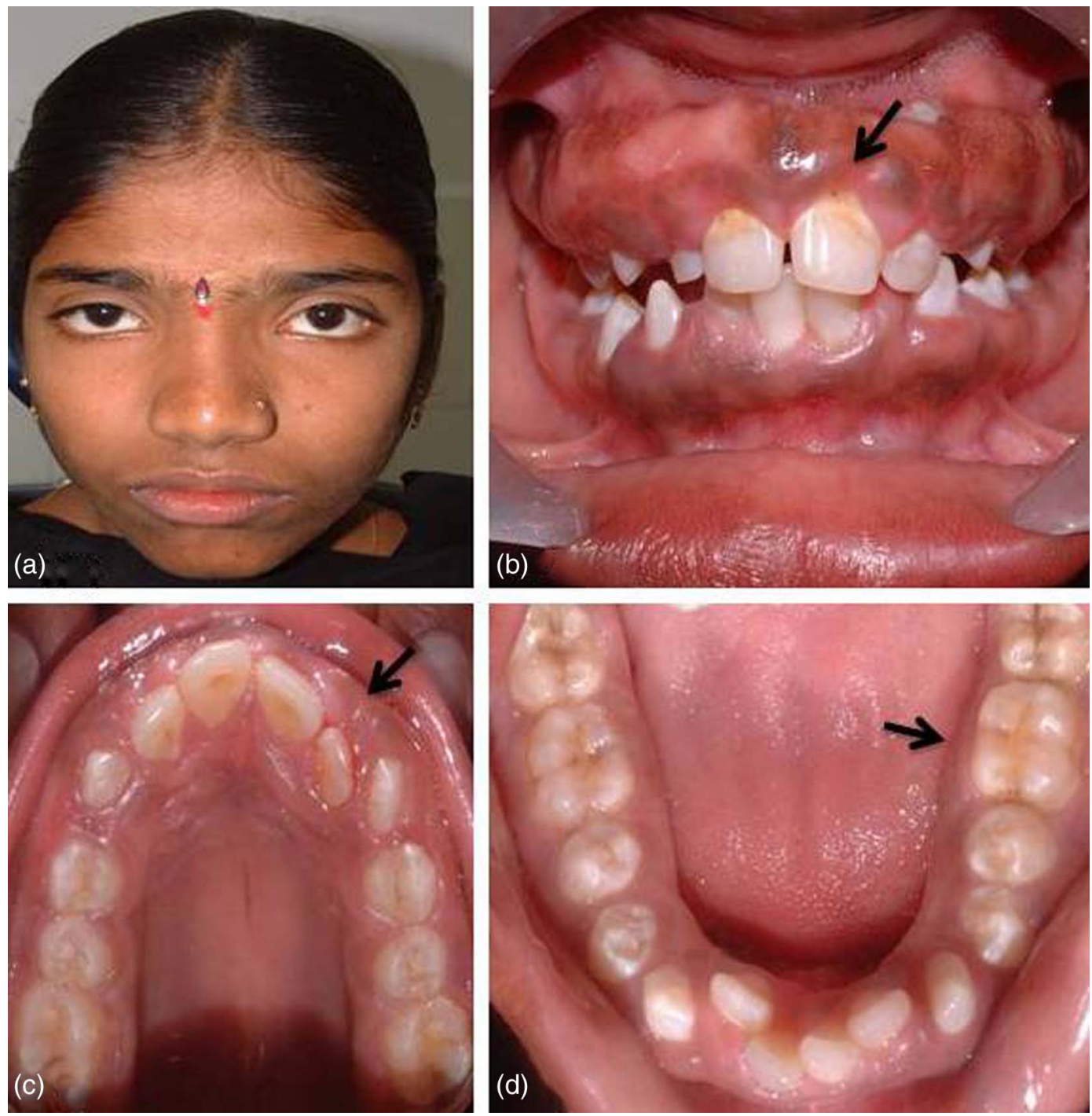

Figure 3 (A-D) Intraoral photograph of the patient's sister revealed generalised, severe gingival overgrowth involving both the mandibular and maxillary arches. The gingival overgrowth was seen as firm, dense, fibrous and painless enlargement with normal gingival colour.

mutation in son of sevenless-1 (SOS-1) gene has been held responsible for this rare hereditary condition. ${ }^{3} 7810$ When this gene is not mutated, it is involved in the growth of normal healthy gums. When mutated results in gingival fibromatosis. ${ }^{10}$ Other possible aetiological factors for HGF are (1) increased proliferation and elevated production of extracellular matrix molecules, type 1 collagen and fibronectin could contribute to the increased bulk of gingiva. ${ }^{6}$ (2) Impairment in extracellular matrix degradation. ${ }^{6}{ }^{12} \mathrm{HGF}$ is clinically characterised by fibrotic gingival overgrowth that covers a large portion of the clinical crowns. ${ }^{11} 12$

The enlargement begins with the emergence of deciduous dentition and gradually increased to cover the teeth completely, delaying the exfoliation of primary molars. Severe growth results in crowding of underlying teeth, speech impairment and difficulty in mastication. ${ }^{3}$ The enlarged gingiva is usually normal in colour, consistency and with a minimal tendency to bleed. It presents with nodular appearance and an abundance of stippling of the attached gingiva. ${ }^{12}$ In our case similar features were evident.

HGF can occur solely affecting the gingiva only, with no other local/systemic involvement and is associated with certain syndromes: Zimmer-man Laband syndrome, Rutherford syndrome, Jones syndrome, Cross syndrome and Raman syndrome. $^{2-9}$

HGF can be diagnosed by its peculiar gingival feature (with or without involvement of associated syndrome) and positive family history. Sometimes histopathological features may prove helpful in strengthening the clinical diagnosis of HGF. ${ }^{10} 1112$

The classical histopathological features of HGF are highly fibrous connective tissue, with haphazardly arranged dense collagen bundles, numerous spindle-shaped fibroblasts and connective tissue that is relatively avascular. Thickened, acanthotic and hyperkeratotic stratified squamous epithelium is also present with elongated rete ridges. Superficial layers of epithelium may occasionally show features of inflammation (oedema). ${ }^{11}{ }^{12}$ Our case report showed similar histological findings.

HGF cannot be cured but may be controlled with varying degree of success. The best time to initiate treatment to HGF is when all of the permanent dentition has erupted because the risk of recurrence is higher before it. Treatments vary according to the degree of severity of gingival enlargement. ${ }^{3} 11$

When the enlargement is mild, thorough scaling of teeth and proper home care may be sufficient to restore good oral health 
and appearance. ${ }^{3}$ However, if scaling is proved to be ineffective and the gingival overgrowth continues to affect appearance and function, surgical intervention becomes mandatory. ${ }^{3} 7$ In case of gingival enlargement with deep pockets and severe loss of underlying alveolar bone, an internal bevel gingivectomy with open flap debridement is indicated. ${ }^{7}$ In areas with inadequate attached gingiva, flap surgery can be carried out. ${ }^{3}$ Gingivoplasty with blades, surgical knives, laser or electrosurgery to restore normal gingival appearance and contours are the treatment of choice. $^{12}$

\section{Learning points}

- Factors to be considered during treatment planning include aesthetic and functional needs, as well as the onset of puberty because recurrence is predominately observed in children and teenagers rather than in adults.

- The degree of gum overgrowth varies considerably, even among members of an affected family. There is variability in the number of teeth involved (extent) and the volume of excess gum (severity).

- Speech and mastication can be affected depending on extend and severity of the overgrowth.

Contributors All authors contributed to the preparation of the manuscript.
Competing interests None.

Patient consent Obtained.

Provenance and peer review Not commissioned; externally peer reviewed.

\section{REFERENCES}

1 Arabi SR, Ebrahimzade Z, Mahdi K, et al. Hereditary gingival fibromatosis: a case report. Res J Biol Sci 2011;6:104-7.

2 Butchi Babu K, Pavankumar K, Anuradha BR, et al. Hereditary gingival fibromatosis-a case report and management using a noval surgical technique. RSBO Revista SulBrasileira de Odontologia 2011;8:453-8.

3 Ramakrishnan T, Kaur M. Multispeciality approach in the management of patient with hereditary gingival fibromatosis:1-year follow up: a case report. Int I Dent 2010;2010:575979.

4 Cholakis AK, Wiltshire WA, Birek C. Treatment and long term follow-up of a patient with hereditary gingival fibromatosis: a case report. J Can Dent Association 2002;68:290-4.

5 Vishnoi SL. Hereditary gingival fibromatosis: report of four generation pedigree. Int $J$ Case Rep Images 2011;2:1-5.

6 Zhou M, Xu L, Meng HX. Diagnosis and treatment of a hereditary gingival fibromatosis case 2011;14:155-8.

7 Chaturvedi R. Idiopathic gingival fibromatosis associated with generalized aggressive periodontitis: a case report. JADC 2009;75:291-5.

8 Jaju PP, Desai A, Desai RS, et al. Idiopathic gingival fibromatosis: case report and its management. Int J Dent 2009:1-6.

9 Harikihan G. Idiopathic fibromatosis of gingival: a case report of hereditary tendency in the same family. I Indian Acad Dent Spec 2010;1:52-4.

10 Nayak PA, Nayak UA, Khandelwal V, et al. Idiopathic gingival fibromatosis. Int J Clin Pediatr Dent 2011;4:77-81.

11 Khan U, Mustafa S, Saleem Z, et al. Hereditary gingival fibromatosis diagnosis and treatment. Pak Oral Dent I 2012;32:226-31.

12 Livada R, Shiloah J. Gummy smile: could it be genetic:hereditary gingival fibromatosis. J Tenn Dent Assoc 2012;92:23-6.

Copyright 2013 BMJ Publishing Group. All rights reserved. For permission to reuse any of this content visit

http://group.bmj.com/group/rights-licensing/permissions.

BMJ Case Report Fellows may re-use this article for personal use and teaching without any further permission.

Become a Fellow of BMJ Case Reports today and you can:

- Submit as many cases as you like

- Enjoy fast sympathetic peer review and rapid publication of accepted articles

- Access all the published articles

- Re-use any of the published material for personal use and teaching without further permission

For information on Institutional Fellowships contact consortiasales@bmjgroup.com

Visit casereports.bmj.com for more articles like this and to become a Fellow 